\section{Combination of Colonoscopy and Clip Application with Angiography to Mark Vascular Malformation in the Small Intestine}

S. Gölder ${ }^{1}$, M. Strotzer ${ }^{2}$, S. Grüne ${ }^{1}$,

C. Züllke ${ }^{3}$, J. Schölmerich ${ }^{1}$,

H. Messmann ${ }^{4}$

${ }^{1}$ Department of Internal Medicine I, University Hospital of Regensburg, Regensburg, Germany

2 Department of Radiology,

University Hospital of Regensburg, Regensburg, Germany

${ }^{3}$ Department of Surgery,

University Hospital of Regensburg, Regensburg, Germany

${ }^{4}$ Department of Internal Medicine III, Zentralklinikum Augsburg, Augsburg, Germany

\section{Corresponding Author}

\section{S. Gölder, M.D.}

Dept. of Internal Medicine I

University of Regensburg

93042 Regensburg

\section{Germany}

Fax: $\quad+49-941-944-7002$

E-mail: stefan.goelder@ klinik.uni-regensburg.de

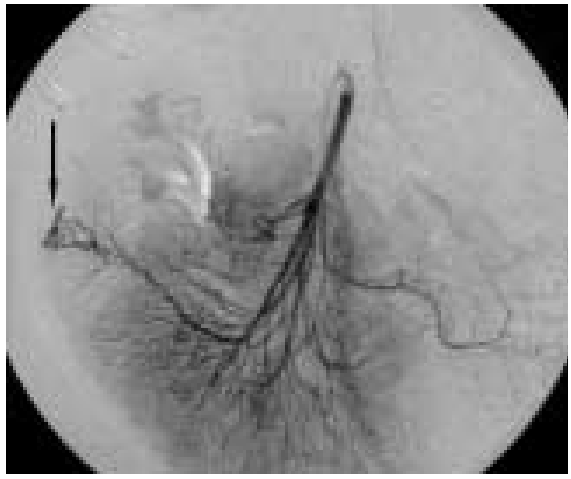

Figure 1 A 55-year-old woman was admitted with chronic recurrent lower gastrointestinal bleeding. Previous examinations, including esophagogastroduodenoscopy and colonoscopy, during an active bleeding episode, revealed no bleeding site. Angiography showed a vascular malformation in projection to the right sided colon or neoterminal ileum (arrow).

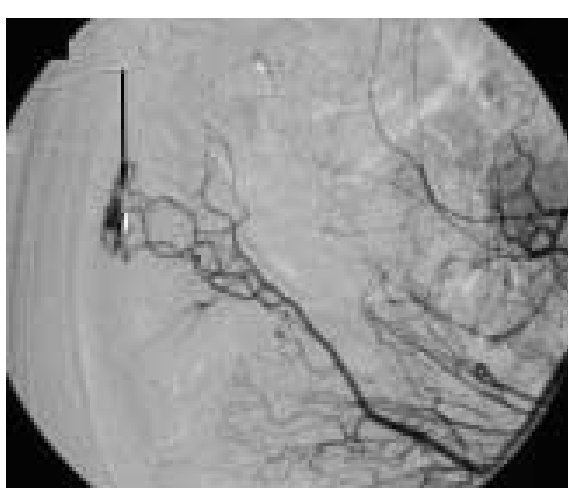

Figure 3 A second angiography was performed, which confirmed the correct identification of the vascular malformation since the clip was visible in projection to the angiographically identified lesion (arrow). In addition, a second vascular malformation was detected during this angiography, which could not be reached by the endoscope. Thus, endoscopic treatment was not practical and surgery was performed.
This article already appeared in the fourth issue of Endoscopy 2003 (Gölder S, Strötzer $\mathrm{M}$, Grüne $S$ et al. Combination of colonoscopy and clip application with angiography to mark vascular malformation in the small intestine. Endoscopy 2003; 35; 378) with the figures in the incorrect order. We would like to apologize to the authors for this error.

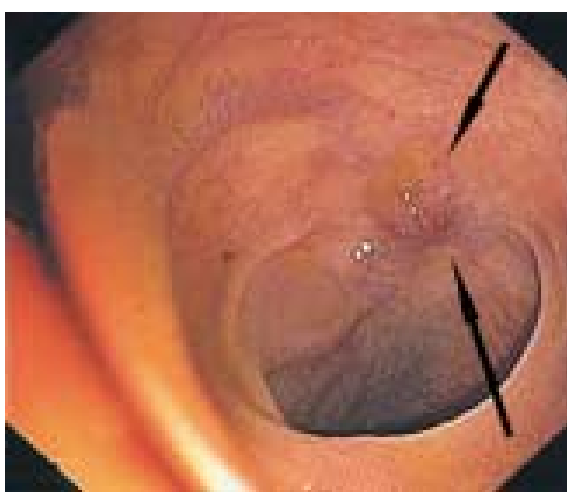

Figure 2 With this lesion in mind one suspicious lesion was found $40 \mathrm{~cm}$ beyond the ileocolonic anastomosis (arrows). The lesion was marked with a clip. 